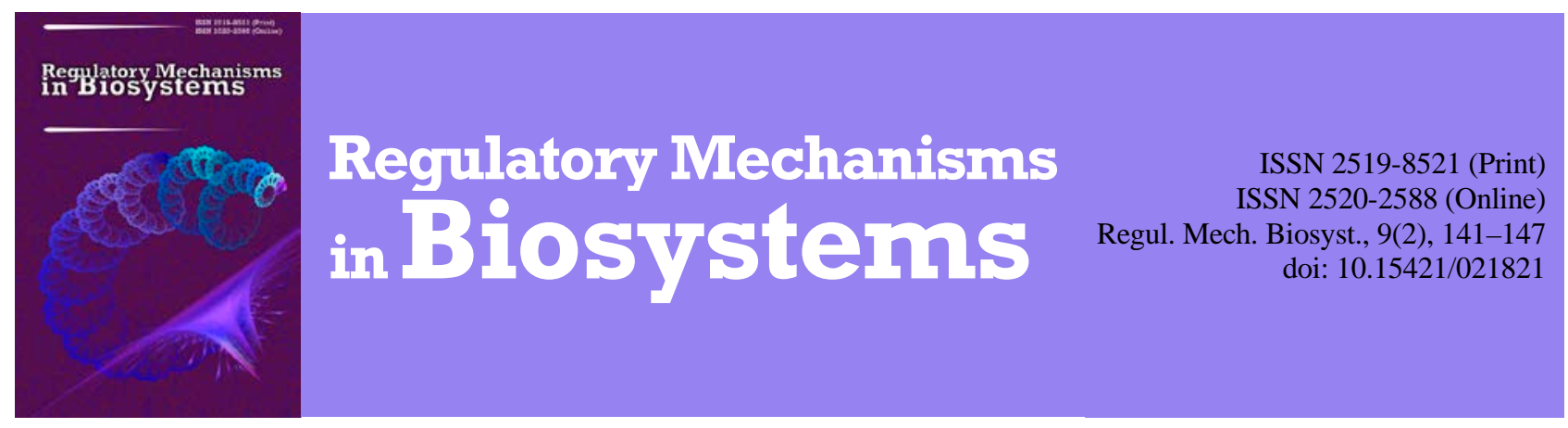

\title{
Biotechnology for obtaining hybrid positive control samples for immunoassay for detecting antibodies against Chlamydia trachomatis
}

\author{
O. Y. Galkin*, Y. V. Gorshunov**, O. B. Besarab*, K. O. Shchurska* \\ *National Technical University of Ukraine "Igor Sikorsky Kyiv Polytechnic Institute”, Kyiv, Ukraine \\ **Research and Technology Institute of Urban Development, Kyiv, Ukraine
}

Article info

Received 15.01.2018

Received in revised form 21.03.2018

Accepted 22.03.2018

National Technical University

of Ukraine "Igor Sikorsky Kyiv

Polytechnic Institute",

Peremohy av., 37,

Kyiv, 03056, Ukraine.

Tel.: +38-044-232-05-46.

E-mail:a.galkin@kpi.ua

Research and Technology

Institute of Urban Development,

Mytropolyta Vasylyia

Lypkovskoho st., 35 ,

Kyiv, 03035, Ukraine

Tel.: +38-044-248-23-39.

E-mail: y.gorshunov@gmail.com
Galkin, O. Y., Gorshunov, Y. V., Besarab, O. B., \& Shchurska, K. O. (2018). Biotechnology for obtaining hybrid positive control samples for immunoassay for detecting antibodies against Chlamydia trachomatis. Regulatory Mechanisms in Biosystems, 9(2), 141-147. doi:10.15421/021821

The enzyme-linked immunosorbent assay (ELISA) is the most informative and versatile method of serological diagnostics. The possibility of detection by ELISA of specific antibodies of different classes allow one to differentiate primary infectious processes and their remission, exacerbation and chronic disease (holding of differential diagnosis). This approach is implemented in the methodology for evaluation of patients for the presence of humoral immune response against TORCH-infections pathogens (toxoplasmosis, rubella, cytomegalovirus, herpes simplex viruses infections, and some others). Therefore, testing for the presence of specific IgG and IgM antibodies against TORCHinfection pathogens in blood serum is an important element of mother and child protection. The essential problem in the production of IgM-capture ELISA diagnostic kits is obtaining positive control. The classic version of positive control is human blood serum (plasma) containing specific antibodies. But specific IgM-positive sera are insignificant raw material. This fact can significantly limit the production of diagnostic kits, especially in case of large-scale manufacture. We have suggested a methodological approach to the use of synthetic positive controls in IgM-capture ELISA kits based on conjugate of normal human IgM and monoclonal antibodies against horseradish peroxidase. It was found that it is possible to realize such a task by means of NHS ester-maleimide-mediated conjugation (by sulfosuccinimidyl-4-(Nmaleimidomethyl)cyclohexane-1-carboxylate), reductive amination-mediated conjugation (by sodium periodate) and glutaraldehyde-mediated conjugation. It was found that conjugates of normal human IgM and monoclonal antibodies against horseradish peroxidase obtained using NHS ester-mediated maleimide conjugation and periodate method are homogeneous in molecular weight, whereas conjugate synthesized by glutaraldehyde method comprises at least three types of biopolymers with close molecular weight. It was found that synthetic positive control obtained by different methods are characterized by higher titre compared to IgM-positive high-titre serum. However, positive control obtained by NHS ester-mediated maleimide conjugation has the best titration profile characteristics. We have suggested a methodological approach to the use of synthetic positive controls in indirect ELISA kits based on conjugate of normal human IgM (IgA) and monoclonal antibodies against major outer membrane protein of Ch. trachomatis. It was found that it is possible to realize such task by means of NHS ester-maleimide-mediated conjugation (by sulfosuccinimidyl-4(N-maleimidomethyl)cyclohexane-1-carboxylate) and reductive amination-mediated conjugation (by sodium periodate). It was found that synthetic positive control obtained by different methods are characterized by higher titre compared to IgM- and IgA-positive high-titre serum. However, positive control obtained by NHS ester-mediated maleimide conjugation has the best titration profile characteristics, both at the release time and after a week's storage at $37^{\circ} \mathrm{C}$.

Keywords: ELISA; human immunoglobulins; synthetic control; Chlamydia trachomatis; conjugation

\section{Introduction}

Laboratory diagnosis is an integral part of the clinical examination of a patient, since without a laboratory examination it is neither possible to establish a clinical diagnosis nor to monitor the effectiveness and safety of therapeutic measures. Among the whole complex of methods of clinical laboratory diagnostics, there are serological methods, which are based on the identification of serological markers (antigens, allergens, antibodies) of infectious (viral, bacterial, fungal, and parasitic) and non-infectious (including autoimmune, allergic, endocrine and oncological) diseases. The most informative, universal and, as a consequence, widespread serology test is the enzyme-linked immunosorbent assay (ELISA) (Nikolaenko et al., 2005; Galkin et al., 2017). The possibility of detecting by means of ELISA specific antibodies of different classes can differentiate the primary infectious process and its remission, exacerbation or chronicization of the disease (that is, to conduct a differential diagnosis). Such an approach is realized in the methodology of patient survey for the presence of a humoral immune response to TORCH-infectious agents (toxoplasmosis, rubella, cytomegaly, herpes simplex virus infections and others) that can infect the fetus and cause developmental defects (Numan et al., 2015; Lu et al., 2016; De Carolis et al., 2017). That is why testing for the presence of specific antibodies against TORCH-infectious agents is an important element in the mother and child protection system.

According to available literature data (Holmes et al., 2005; Vazquez et al., 2007; Hunsperger et al., 2009), many of ELISA kits for the detection of specific IgM antibodies against certain pathogens in human serum (plasma) infectious diseases are constructed according to the principle of IgM-capture assay. This modification of ELISA allows for the first stage to fix the total pool of IgM antibodies on the solid phase (the concentration of which in serum is much less than the content of 
IgG), and the second - the detection of specific IgM. In other cases (Reesink-Peters et al., 2001; Kamel, 2013; Galkin et al., 2018), there are immuno-enzyme kits, in particular for the detection of specific IgM and IgA antibodies to Chlamydia trachomatis in human serum (plasma), based on the principle of indirect ELISA.

Obtaining positive controls (PCs) is a significant problem in the production of diagnostic kits intended for the detection of IgA and IgM specific antibodies against different pathogens (including $C h$. trachomatis infection). The classic version of PC is the serum (plasma) of human blood containing specific antibodies of a certain class. However, the frequency of detection of IgA- and IgM-positive sera is negligible. The relevant biological material as a raw material for obtaining PC is extremely scarce. This circumstance can significantly limit the production of diagnostic kits, especially in the context of large-scale production.

In order to increase the efficiency of ELISA test kits production, we proposed a methodological approach that addresses the use of synthetic PCs: for the ELISA test kits based on the principle of IgM-capture assay the use of a conjugate of normal immunoglobulins of the IgM class and monoclonal antibodies (McAbs) to the enzyme horseradish peroxidase (HRP); and for the ELISA test kit for the diagnosis of urogenital chlamydia, based on the principle of indirect ELISA, - the use of a conjugate of IgM (IgA) normal immunoglobulins and McAbs to Ch. trachomatis major external membrane protein (MOMP).

The aim of the work was to develop the biotechnological approach for hybrid (synthetic) positive control samples for the ELISA test kits based on IgM-capture modification, as well as on the indirect variant for the detection of IgA and IgM antibodies to Ch. trachomatis.

\section{Materials and methods}

NHS ether-maleimide-mediated conjugation. Synthesis of the conjugate was performed using the basic method (Hermanson, 2008) with our own modifications. In the first step, activation of the normal human IgM was carried out by NHS ester-maleimide cross-linker - sulfo-succinimidyl-4-(N-maleimidomethyl)cyclohexane-1-carboxylate (sulfoSMCC). $2-3 \mathrm{ml}$ of a solution of IgM $(400-420 \mathrm{mg} / \mathrm{ml})$ was used in $0.1 \mathrm{M}$ phosphate saline buffer with $0.15 \mathrm{M} \mathrm{NaCl}, \mathrm{pH} 7.2$ (PBS). To the solution of immunoglobulins, $6 \mathrm{mg}$ of sulfo-SMCC was added, stirred until complete dissolution, and held for $30 \mathrm{~min}$ at room temperature. The unreacted sulfo-SMCC compartment was conducted on a column of $2.5 \times 100 \mathrm{~cm}$ with sephacryl S-300 using PBS. Active immunoglobulins were eluted from the column, diluted to a concentration of $20 \mathrm{mg} / \mathrm{ml}$, and immediately used for synthesis of the conjugate.

The conjugation of activated IgM and McAbs with reduced sulfhydryl groups was carried out as follows. A solution of McAbs against $\mathrm{HRP}$ with a concentration of $5 \mathrm{mg} / \mathrm{ml}$ was used in PBS with $10 \mathrm{mmol} / \mathrm{L}$ EDTA. $18 \mathrm{ml}$ of mercaptoethylamine (MEA) was added to $3 \mathrm{ml}$ of McAbs solution, incubated for $90 \mathrm{~min}$ at a temperature of $37^{\circ} \mathrm{C}$. A $1.5 \times 40 \mathrm{~cm}$ chromatography column with Sephadex G-25 (Pharmacia Biotech) using PBS with $10 \mathrm{mmol} / \mathrm{l}$ EDTA was used for separation of non-reactive MEA. The elution of the reduced antibodies was performed at a rate of $2 \mathrm{ml} / \mathrm{min}$. Fractions were collected in a volume of $0.5 \mathrm{ml}$ and the optical density (OD) was measured at $280 \mathrm{~nm}$. The collected fractions of reduced McAbs were immediately mixed with activated human IgM in a molar ratio of IgM : McAbs equal to $1: 4$. The reaction mixture was maintained at room temperature for $2 \mathrm{~h}$. The resulting conjugate was purified by immunoaffinity chromatography on a 6-B Sepharose column, which immobilized McAbs against horseradish peroxidase (HRP).

Periodate conjugation method. Conjugation of McAbs against HRP with normal human IgM was performed in a molar ratio of McAbs to IgM $1: 1$ by periodate oxidation (Tijssen, 1985) with our own modifycations (Galkin et al., 2013). At oxidation of human IgM (15 mg/ml), $0.1 \mathrm{M}$ bicarbonate buffer, $\mathrm{pH}$ 8.3, was used, adding the same volume of $14 \mathrm{mM}$ aqueous solution of sodium periodate. The mixture was incubated for $2 \mathrm{~h}$ at room temperature. The thus obtained solution of activated human IgM was added to a solution of McAbs, which was pre-dialyzed against a $0.1 \mathrm{M}$ carbonate solution, $\mathrm{pH}$ 9.2. The mixture was transferred to a chromatographic column and 1/3 part of dry sephadex G-25 was added and incubated for $3 \mathrm{~h}$ at room temperature. Upon completion of the incubation, the conjugate solution was eluted from the column and the reaction stopped by the addition of $1 / 20$ parts by volume of aqueous $\mathrm{NaBH}_{4}$ solution $(5 \mathrm{mg} / \mathrm{ml})$, leaving for $30 \mathrm{~min}$ at room temperature. After that, 3/20 parts of sodium hydroxide solution was added, incubated for $60 \mathrm{~min}$. The resulting conjugate solution was transferred to a $0.02 \mathrm{M}$ phosphate buffer with $0.15 \mathrm{M} \mathrm{NaCl}$ by dialysis.

Conjugation with glutaraldehyde. Synthesis of the conjugate was performed using a basic two-step method (Hermanson, 2008) with our own modifications. A human IgM solution at a concentration of $10 \mathrm{mg} / \mathrm{ml}$ in the PBS, $\mathrm{pH}$ 6.8, was used. Glutaraldehyde was added to the solution of the immunoglobulin to glutaraldehyde final concentration of $1 \%$ and maintained overnight at room temperature. Purification of the activated immunoglobulin from the excess of glutaraldehyde was carried out using gel filtration on a column of $2.5 \times 100 \mathrm{~cm}$ with sephacryl S-300 using PBS, pH 6.8. For further conjugation, a solution of McAbs to HRP was used at a concentration of $10 \mathrm{mg} / \mathrm{ml}$ in $0.5 \mathrm{M}$ carbonate buffer solution, $\mathrm{pH}$ 9.5. The activated human IgM was mixed with McAbs in a molar ratio of $1: 1$ and maintained overnight at $4{ }^{\circ} \mathrm{C}$. The restoration of Schiff bases and probable traces of glutaraldehyde was carried out by adding $\mathrm{NaBH}_{4}(10 \mathrm{mg} / \mathrm{ml})$ and holding for $1.5 \mathrm{~h}$ at $4^{\circ} \mathrm{C}$. To separate the probable insoluble forms, the solution of the resulting conjugate was centrifuged at 10,000 rpm and purified on a column of $2.5 \times 100 \mathrm{~cm}$ with sephacryl S-300 using PBS, pH 7.4.

IgM-capture ELISA. Monoclonal antibodies specific to human IgM were sorbed in a $0.02 \mathrm{M}$ carbonate-bicarbonate buffer at a concentration of $2 \mu \mathrm{g} / \mathrm{ml}$ on a 96-well polysterol plate for high-sorption capacity ELISA (Suzhou Conrem Biomedical Technology Co., China). The plate was incubated for $12 \mathrm{~h}$ at $4{ }^{\circ} \mathrm{C}$, then washed three times with $0.02 \mathrm{M}$ phosphate buffered saline with $0.15 \mathrm{M} \mathrm{NaCl}$ and $0.2 \%$ Tween-20 (PBST) and kept in a solution of bovine serum albumin (BSA) (10 mg/mL in PBS) for $1 \mathrm{~h}$ at $37^{\circ} \mathrm{C}$. After four-fold well washings with PBST, the plate was filled with $100 \mu$ of a solution of normal IgM and McAbs to HRP in a reaction buffer solution (0.05 M tris-HCl buffer, pH 8.0, $0.15 \mathrm{M} \mathrm{NaCl}, 5 \mathrm{mM}$ EDTA, 0, $5 \mathrm{mg} / \mathrm{ml} \mathrm{BSA}, 0.2 \%$ Tween20). The plates were incubated for $30 \mathrm{~min}$ at $37^{\circ} \mathrm{C}$ and washed 4 times with PBST. After washing, a solution of the conjugate of Ch. trachomatis recombinant antigens and HRP $(100 \mu \mathrm{l} /$ well $)$ was added, which was incubated for $30 \mathrm{~min}$ at a temperature of $37^{\circ} \mathrm{C}$. Plates were three times washed with PBST and twice with distilled water, and then $100 \mu \mathrm{l}$ of substrate-chromogenic mixture (solution of 3,3',5,5'-tetramethylbenzidine $0,25 \mathrm{mg} / \mathrm{ml}$ in $0,1 \mathrm{M}$ sodium citrate buffer, $\mathrm{pH} \mathrm{4,5}$, with addition of $10 \mu \mathrm{l}$ of a $33 \%$ solution of hydrogen peroxide). The reaction was displayed for $20 \mathrm{~min}$ in the dark and stopped by adding $50 \mu \mathrm{l}$ of $2 \mathrm{M}$ sulfuric acid. The optical density was measured at $450 \mathrm{~nm} / 620 \mathrm{~nm}$.

Indirect ELISA. The recombinant MOMP was adsorbed in a $0.02 \mathrm{M}$ carbonate bicarbonate buffer at a concentration of $2 \mu \mathrm{g} / \mathrm{ml}$ on a $96-w e l l$ polysterol plate for high-sorption capacity ELISA (Suzhou Conrem Biomedical Technology Co., China). The plate was incubated for $12 \mathrm{~h}$ at $4{ }^{\circ} \mathrm{C}$, then washed three times with PBST and kept in a solution of BSA $\left(10 \mathrm{mg} / \mathrm{mL}\right.$ in PBST) for $1 \mathrm{~h}$ at $37^{\circ} \mathrm{C}$. After four-fold washings with PBST, the wells were filled with $100 \mu$ of a solution of the conjugate of normal human IgM (IgA) and McAbs to the MOMP in a reaction buffer solution (0.05 M tris-HCl buffer, $\mathrm{pH} 8.0,0.15 \mathrm{M} \mathrm{NaCl}$, $5 \mathrm{mM}$ EDTA, $0.5 \mathrm{mg} / \mathrm{ml}$ BSA, $0.2 \%$ Tween-20). The plates were incubated for $30 \mathrm{~min}$ at $37^{\circ} \mathrm{C}$ and washed 4 times with PBST. After washing, a solution of peroxidase conjugate of monoclonal antibodies to human IgM (IgA) $(100 \mu 1 /$ well) was added which was incubated for $30 \mathrm{~min}$ at a temperature of $37^{\circ} \mathrm{C}$. The following procedure was similar to the IgM-capture analysis.

\section{Results}

Characteristics of biological components. The following biological components were required for synthetic positive controls: monoclonal antibodies against HRP and Ch. trachomatis MOMP; purified preparations of human IgA and IgM. Some of these components were obtained by us earlier. The characteristics of the panels of monoclonal antibodies against are shown in Table $1-2$. Table 1 presents the results of the study 
of the specificity of anti-HRP McAbs - testing of supernatants of hybridomas' clones to: apoenzyme (apoHRP), chemically modified (modHRP) and recombinant (deglycosylated) enzyme (rHRP). McAbs were divided into three groups of specificity: group I was characterized by positive signals when tested for all variants of the enzyme; group II was characterized by positive signals when testing only on native HRP; group III was represented by 1 clone, which was characterized by positive signals when tested for native and chemically modified HRP (195C10). Consequently, the first group of antibodies is directed to the protein part of the antigen, the second group is directed to the carbohydrate residues attached to the HRP, and the third group is specific to the prosthetic group of the enzyme. The composite characteristic of McAbs (ELISA activity, isotype, titre and affinity constant) allowed us to form the
McAbs panel, which is promising for the development of biotechnology for hybrid positive control samples for immunoassay analysis. The characterization of the McAbs by titre and affinity made it possible to assess the prospects for the use of such McAbs in immunoassay. The isotype of antibodies, on the one hand, affects the feasibility of using McAbs in various bioanalytical methods, and, on the other hand, is an important prerequisite for choosing the next method of isolation and antibodies purification. The developed antibody panel included only those with a high titre $(\geq 1: 400)$ and an affinity constant $\left(\geq 8.0 \times 10^{9} \mathrm{M}^{-1}\right)$, as well as an intense signal from the indirect ELISA.

Other biological components used to achieve this goal were monoclonal antibodies to the main protein of the Ch. trachomatis outer membrane; their characteristics are given in Table. 2.

Table 1

Characteristics of the panel monoclonal antibodies to the horseradish peroxidase

\begin{tabular}{|c|c|c|c|c|c|c|c|c|c|}
\hline \multirow[b]{2}{*}{ McAbs } & \multicolumn{4}{|c|}{$\mathrm{OD}^{1)}$ in indirect ELISA when testing on } & \multirow[b]{2}{*}{ Isotype } & \multirow[b]{2}{*}{ Titre $^{1)}$} & \multirow{2}{*}{$\begin{array}{c}\text { Affinity } \\
\text { constant }^{1)}, 10^{9} \\
\mathrm{M}^{-1} \\
\end{array}$} & \multirow[b]{2}{*}{ Epitope } & \multirow{2}{*}{$\begin{array}{l}\text { Group of } \\
\text { epitope } \\
\text { specificity }\end{array}$} \\
\hline & nHRP & apoHRP & modHRP & rHRP & & & & & \\
\hline $192 \mathrm{~F} 10$ & 1.542 & 1.472 & 1.242 & 1.117 & $\mathrm{IgG}_{2 \mathrm{~b}}$ & $1: 400$ & 11.3 & $\mathrm{P} 1$ & $\mathrm{I}$ \\
\hline 193C7 & 1.466 & 1.561 & 1.334 & 1.241 & $\operatorname{IgG}_{2 b}$ & $1: 400$ & 9.0 & P3 & I \\
\hline 196B7 & 2.071 & 2.119 & 1.815 & 1.091 & $\operatorname{IgG}_{1}$ & $1: 800$ & 20.0 & P2 & I \\
\hline 191D5 & 2.341 & 2.048 & 0.050 & 0.099 & $\operatorname{IgG}_{2 \mathrm{a}}$ & $1: 800$ & 20.0 & P4.2 & II \\
\hline $194 \mathrm{H} 10$ & 1.574 & 1.120 & 0.079 & 0.025 & $\mathrm{IgG}_{3}$ & $1: 800$ & 12.7 & P4.1 & II \\
\hline 195D5 & 1.943 & 1.777 & 0.033 & 0.045 & $\operatorname{IgG}_{2 \mathrm{~b}}$ & $1: 1600$ & 37.4 & P4.1 & II \\
\hline 197F4 & 2.348 & 1.325 & 0.054 & 0.031 & $\operatorname{IgG}_{2 \mathrm{a}}$ & $1: 800$ & 6.5 & P5.1 & II \\
\hline 195C10 & 2.324 & 0.220 & 1.042 & 0.072 & $\operatorname{IgG}_{2 \mathrm{a}}$ & - & - & - & III \\
\hline 213B3 & 1.988 & 1.544 & 1.891 & 1.405 & $\operatorname{IgG}_{2 \mathrm{~b}}$ & $1: 800$ & 12.0 & P1 & I \\
\hline $213 F 7$ & 2.025 & 1.974 & 1.744 & 1.465 & $\operatorname{IgG}_{1}$ & $1: 800$ & 11.5 & P2 & I \\
\hline 211F9 & 2.565 & 2.272 & 0.063 & 0.047 & $\mathrm{IgG}_{3}$ & $1: 1600$ & 10.0 & P4.2 & II \\
\hline 212H8 & 2.221 & 2.144 & 0.047 & 0.052 & $\operatorname{IgG}_{2 \mathrm{a}}$ & $1: 1600$ & 28.5 & P4.2 & II \\
\hline $214 \mathrm{C} 4$ & 1.994 & 1.754 & 0.035 & 0.034 & $\mathrm{IgG}_{1}$ & $1: 800$ & 19.0 & P4.2 & II \\
\hline 215B8 & 1.758 & 1.621 & 0.073 & 0.136 & $\operatorname{IgG}_{1}$ & $1: 400$ & 17.5 & P5.3 & II \\
\hline 215G7 & 1.533 & 1.602 & 0.035 & 0.055 & $\mathrm{IgG}_{1}$ & $1: 800$ & 18.2 & P4.1 & II \\
\hline
\end{tabular}

Note: ${ }^{1)}$ - the average values of the quantities based on the results of the study of hybridoma supernatants in 4 replicates are given $(\mathrm{P}<0.05)$.

For isolation and purification of human IgM, the following scheme was used: serum passing through column with immobilized mouse McAbs of another specificity; serum brought into the immunoaffinity column with anti-IgM McAbs; washing the column with phosphate buffer; elution of IgM with magnesium chloride; washing the column with phosphate buffer; transfer of IgM to phosphate buffer on sephadex G-25. This scheme of immunoaffinity allocation and purification of human IgM allows us to get well-reproduced results when using differrent serums. The original scheme has tangible advantages compared with the schemes based on nonspecific biochemical and physico-chemical methods of isolating this immunoglobulin. It does not require significant amounts of serum, the loss of the target product is minimized, and the technique as a whole is simpler. The degree of purity obtained by this scheme of IgM does not vary from batch to batch and reaches about $100 \%$, which makes possible its use for immunization of animals and immunoassay. Obtaining human IgA was carried out in a fundamentally similar scheme.

Obtaining of synthetic positive controls for the IgM-capture immunoassay. The purpose of the first stage of work was the comparative characterization of various methods of bioconjugation as a method of synthesis of hybrid positive controls for the immunoassay test kits of the IgM-capture modification, based on the evaluation of the biochemical and immunochemical properties of the resulting bioconjugates.

The possibility of detecting by means of ELISA-specific antibodies of different classes can differentiate the primary infectious process and its remission, exacerbation or chronicization of the disease, that is, to conduct a differential diagnosis. This approach is realized when patients are examined for the presence of a humoral immune response to TORCH infections (toxoplasmosis, rubella, cytomegaly, herpes simplex virus infections, and some others) that can infect the fetus and cause developmental defects (Numan et al., 2015; Lu et al., 2016; De Carolis et al., 2017). That is why testing for the presence of specific IgG and IgM antibodies against TORCH-infectious agents is an important diagnostic approach in the mother and child protection system.
Table 2

Characteristics of the panel monoclonal antibodies to Ch. trachomatis MOMP

\begin{tabular}{|c|c|c|c|c|c|}
\hline McAbs & $\begin{array}{l}\mathrm{OD}^{1)} \text { in } \\
\text { indirect } \\
\text { ELISA }\end{array}$ & Isotype & Titre $^{1)}$ & $\begin{array}{c}\text { Affinity } \\
\text { constant }^{1)}, 10^{9} \mathrm{M}^{-1}\end{array}$ & $\begin{array}{c}\text { Competition with } \\
\text { polyclonal } \\
\text { antibodies }\end{array}$ \\
\hline 291B2 & 2.588 & $\operatorname{IgG}_{2 \mathrm{a}}$ & $1: 800$ & 16.0 & - \\
\hline 291F8 & 2.805 & $\operatorname{IgG}_{2 \mathrm{a}}$ & 1:1600 & 16.0 & + \\
\hline 293C8 & 2.496 & $\operatorname{IgG}_{1}$ & 1:800 & 8.0 & - \\
\hline 293D2 & 2.402 & $\operatorname{IgG}_{1}$ & $1: 800$ & 8.0 & - \\
\hline 293F4 & 2.789 & $\operatorname{IgG}_{2 \mathrm{a}}$ & 1:1600 & 16.0 & ++ \\
\hline 294F5 & 2.602 & $\operatorname{IgG}_{2 b}$ & 1:800 & 8.0 & + \\
\hline 296B11 & 2.407 & $\operatorname{IgG}_{2 \mathrm{a}}$ & $1: 800$ & 8.0 & + \\
\hline 296G2 & 2.890 & $\operatorname{IgG}_{2 \mathrm{a}}$ & 1:1600 & 16.0 & - \\
\hline 296H8 & 2.224 & $\operatorname{IgG}_{2 \mathrm{a}}$ & 1:800 & 16.0 & + \\
\hline
\end{tabular}

Note: ${ }^{1)}$ - the average values of the quantities based on the results of the study of hybridoma supernatants in 4 replicates are given $(\mathrm{P}<0.05)$.

Based on literature data and our own experience (Galkin et al., 2013; Dovgan et al., 2016; Yang et al., 2016; Kalayu Yirga et al., 2017), we selected three principal methodological approaches for the synthesis of antibody-antibody conjugates that was evaluated for the synthesis of the appropriate PCs (non-specific IgM/IgA + anti-HRP McAbs): 1) NHS ether-maleimide mediated conjugation on the example of succinimidyl 4-(N-maleimidomethyl) cyclohexane-1-carboxylate (SMCC) as a cross linker; 2) glutaraldehyde method; 3) periodate conjugation method. The use of the above methodological techniques is possible through the following prerequisites. NHS ether-maleimide conjugate-mediated conjugation is possible with the participation of two biomolecules, one of which has free amino groups, and the other has free sulfhydryl groups (Fig. 1). Obviously, human IgM and mouse monoclonal antibodies have appropriate groups that can be involved in this technique. Glutaraldehyde reacts with $\varepsilon$-amino groups of lysine residues of the protein molecule. It is important to note that several reactions occur simultaneously, the result of which is the formation of a product that contains stronger chemical bonds than Schiff simple bases (Hermanson, 
2008). The potential possibility of using the trial method is due to the fact that the human IgM molecule contains up to $12 \%$ of carbohydrate residues (Nikolayenko et al., 2005). This, in turn, allows for the modifycation of the IgM molecule to form active aldehyde groups, which will subsequently react with amino groups of antibodies to form the Schiff base. Aldehyde groups in the IgM molecule are formed by oxidation of sodium periodate of their carbohydrate components, amino groups which are pre-blocked or 1-fluoro-2,4-dinitrobenzene, or protonated (Hermanson, 2008). Thus, we should in practice evaluate the acceptability of these techniques for the synthesis of antibody-antibody bioconjugates.

Let's dwell on the choice of McAbs specific to the horseradish peroxidase, which will be used to synthesize the corresponding hybrid (synthetic) controls for ELISA kits. When forming the selection criteria, the following was taken into account. First, among all the immunochemical McAbs characteristics, which were pre-established (Table 1), the affinity of antibodies is the most important, since this property to a large extent depends on the stability of the immunochemical complex, which includes HRP, anti-HRP McAbs, human normal IgM. Secondly, their equally important characteristic of anti-HRP McAbs is their epitope specificity. Monoclonal antibodies directed to the carbohydrate residues of HRP (P4 and P5 epitopic regions) are characterized by higher affinity constants, compared to McAbs that interact with the polypeptide chain of the enzyme (P1, P2, and P3 epitopic regions). At the same time, the constants of affinity for all the McAbs are rather large $\left(10^{9}-10^{10} \mathrm{M}^{-1}\right)$. It should be noted that the McAbs of both groups of epitopic specificities from the theoretical point of view is promising for the creation of hybrid controls on their basis. Possible limitations include the following. A part of the carbohydrate residues of the enzyme may not be available for interaction with anti-HRP antibodies, since the formation of a peroxidase conjugate is the most important method precisely because of the carbohydrate residues of the enzyme. At the same time, the interaction of anti-HRP antibodies with the protein part of the enzyme may potentially change the enzyme activity.

Based on the foregoing, among the obtained anti-HRP McAbs panel, we have chosen the most affinity antibodies directed both to carbohydrate (McAb 195D5) and to the polypeptide portion (McAb 196B7) of the enzyme of horseradish peroxidase. The further tactic of research was as follows: parallel assessment of synthetic control based on each individual McAb, as well as on the basis of their mixture. At the same time, this unit of research was preceded by a comparative assessment of various methods for obtaining conjugates of murine McAbs to normal human immunoglobulins.

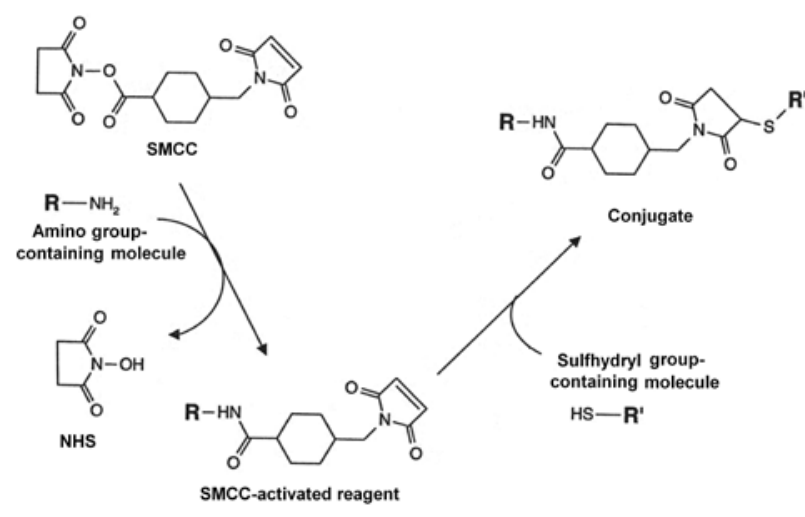

Fig. 1. Principle of SMCC mediated bioconjugation (by Hermanson, 2008)

Fig. 2 shows the results of the isolation of reduced (monovalent) anti-HRP McAbs 196B7 and mercaptoethylamine (MEA) residues by gel filtration on Sephadex G-25 in the production of a NHS-ethermaleimide-mediated method. As seen from the chromatogram, the reduced antibodies emerged from the column in the form of a clear homogeneous molecular weight of the peak. The non-reactive MEA, which is smaller than its molecular weight, descended from the chromatographic column somewhat.

The results of purification of the conjugate obtained by glutaraldehyde, gel filtration on sephacryl S-300 (Fig. 3) were interesting. The re- sulting conjugate was not homogeneous in molecular weight: it detected at least three groups of conjugated molecules with close molecular weights. Similar studies with the conjugate obtained using the instant method were not carried out, since previous studies indicated the conjugates of the homogeneous composition (Nikolaenko et al., 2005).

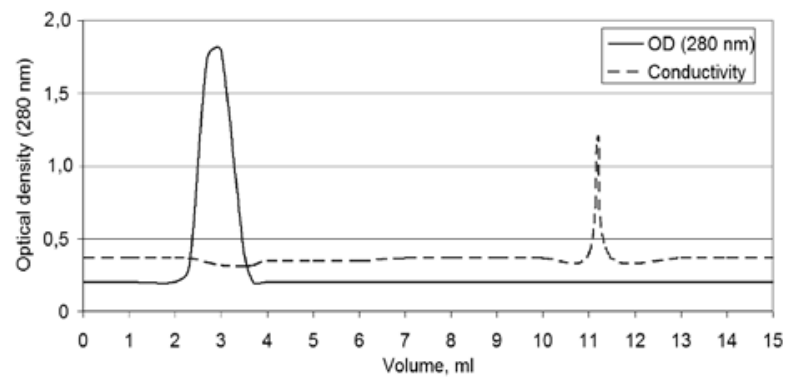

Fig. 2. Isolation of reduced anti-HRP McAbs 196B7 and mercaptoethylamine residues by gel filtration on Sephadex G-25 (NHS ether-maleimide-mediated conjugation)

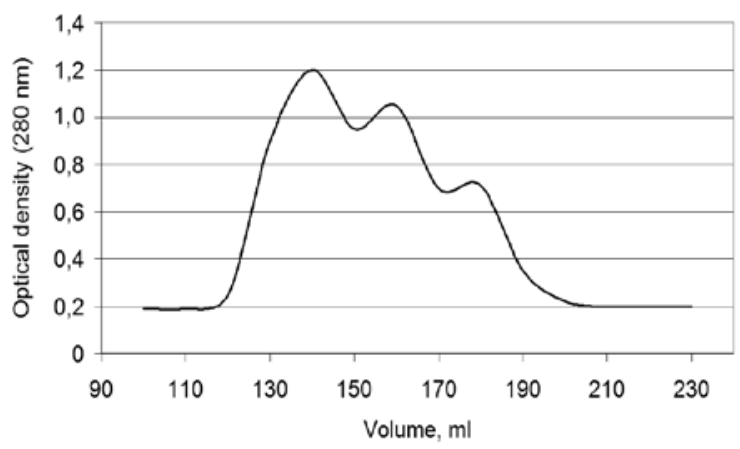

Fig. 3. Final gel filtration purification (Sephacryl S-300) of the antibody-antibody conjugate obtained by the glutaraldehyde method

Hybrid positive controls obtained by different methods were evaluated by titration in an enzyme-linked immunosorbent assay designed to detect IgM antibodies to the $C h$. trachomatis that we developed earlier. This study was conducted in comparison with titration of high-titrated serum containing IgM specific to $C h$. trachomatis, as well as negative serum (Fig. 4).

The results of the experiment showed the following: the best result was the PCs obtained by means of SMCC as a cross-linker (NHS-ethermaleimide-mediated conjugation); the decrease in the activity of diluted PCs obtained by other methods was more intense. At the same time, all variants of synthesized PCs were characterized by a more favourable signal in the ELISA than high-titrer IgM-positive serum.

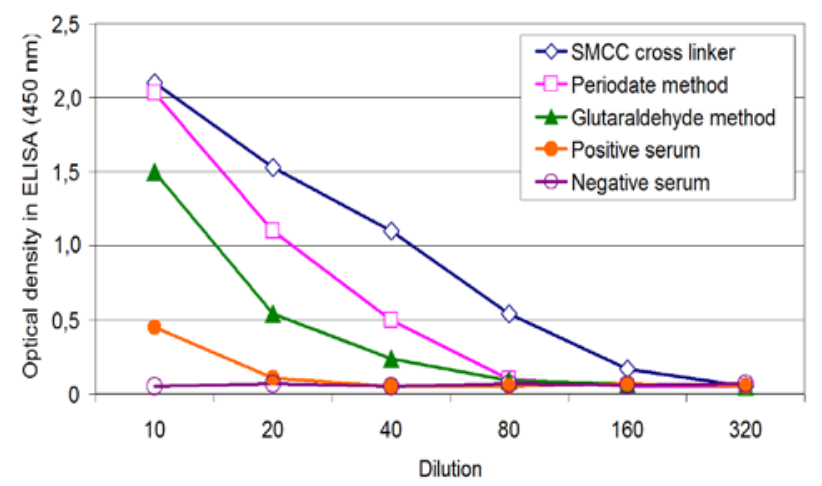

Fig. 4. Titration of hybrid positive controls based on McAb 196B7, obtained by different methods

At the next stage, titration of the hybrid positive controls obtained by the NHS-ester-maleimide-mediated method based on monoclonal antibodies 195D5 and 196B7, as well as their mixtures, was performed 
(Fig. 5). Consequently, synthetic controls based on 195D5 (epitope P4.1 on the carbohydrate part of HRP) and 196B7 (epitope P2 on the protein part of HRP) show comparable results, while synthetic control based on a mixture of these McAbs at small dilutions $(1: 10 \ldots 1: 20)$ provides a truly better result. Thus, the use of a McAb mixture aimed at different chemical properties of parts of the horseradish peroxidase for the synthesis of hybrid positive controls is justified.

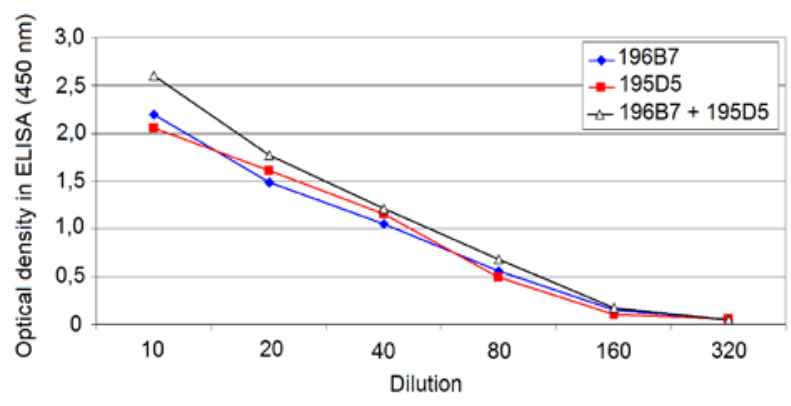

Fig. 5. Titration of synthetic controls obtained by the NHS-ether-maleimide-mediated method on the basis of different McAbs and their mixtures

Assessment of bioconjugation techniques for hybrid positive ELISA controls for detecting IgA and IgM antibodies to Ch. trachomatis. The purpose of the second stage of work was to compare the various methods of bioconjugation for the synthesis of hybrid positive controls of immune enzyme kits for detection of IgA and IgM antibodies to Ch. trachomatis, based on indirect ELISA. To evaluate the hybrid controls obtained, their immunochemical properties were used.

We have already described in detail the methodological approaches that can be used to synthesize antibody-antibody type conjugates (in this case, nonspecific human IgM/IgA + murine McAb to Ch. trachomatis MOMP). The most suitable methods are NHS-ester-maleimidemediated conjugation with succinimidyl-4-(N-maleimidomethyl) cyclohexane-1-carboxylate (SMCC) as a cross-linking agent, as well as a reagent method (restorative amination). Thus, at this stage of work it was necessary in practice to evaluate the acceptability of these techniques for the synthesis of synthetic PCs of ELISA kits for detection of IgA and IgM antibodies to Ch. trachomatis.

In the synthesis of synthetic positive controls, anti-HPP McAb 296G2 was used. The main prerequisite for the use of this particular antibody was that McAb 296G2 did not show active competition with polyclonal antibodies from serum of $C h$. trachomatis infected individuals, which, in turn, minimized the likelihood of PC competition for the site of binding to antigen that is sorbed to the solid phase or steric constraints in such interaction.

Hybrid PCs obtained by different methods were evaluated by titration in an enzyme-linked immunosorbent assay for detection of IgM and IgA antibodies to the urogenital chlamydial pathogen. This study was conducted in comparison with the titration of highly traceable serum containing relevant specific antibodies, as well as negative serum (Fig. 6). The results of the experiment indicated the following: the best result was a PC obtained by means of SMCC as a cross-linker (NHSether-maleimide-mediated conjugation). Decrease of immunological activity at dilution of the PC, obtained by the first method, was more intense. At the same time, all variants of the received PCs were characterized by a more favourable signal in the ELISA than high-titled IgM and IgA-positive serums.

Similar studies were carried out after a test of accelerated stability (storage for a week at a temperature of $37^{\circ} \mathrm{C}$ ). The results of the corresponding tests (Fig. 7) showed that the decrease in the activity of hybrid PCs occurs less slowly than the positive serums containing the corresponding specific antibodies. Such results determine the promising use of the described method for the development and production of immuno-enzyme kits for the diagnosis of urogenital chlamydiosis.

Thus, at this stage of work, methodological approaches to obtaining hybrid positive controls for indirect immunoassay analysis, which are intended to detect IgM and IgA antibodies to the pathogen of urogenital chlamydia, have been substantiated, namely: NHS-ether-maleimidemediated conjugation on an example of SMCC as a cross-linking agent and periodate method of bioconjugation. It has been established that hybrid positive controls, obtained by different methods, are characterized by a higher titre compared to high-titre serum containing IgM and IgA antibodies to $C h$. trachomatis. However, the positive control obtained by means of SMCC was characterized by the best titration profile (a slower decrease in the activity of the ELISA during its dilution) both at the time of its obtaining and after its storage at increased temperature.

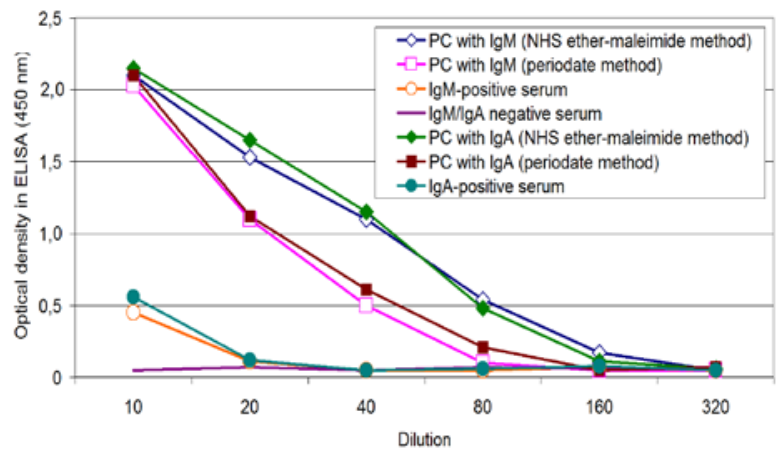

Fig. 6. Titration of synthetic controls obtained by different methods

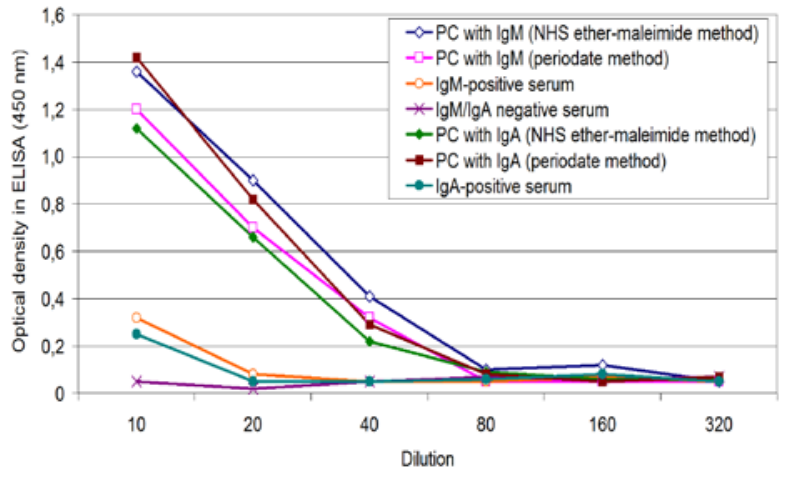

Fig. 7. Titration of hybrid controls obtained by different methods after its storage at $37^{\circ} \mathrm{C}$

\section{Discussion}

Among the whole complex of methods of clinical laboratory diagnostics, one of the earliest surgical methods of serologic diagnostics was proposed and introduced, which remain extremely relevant to the present day. Serological methods are used for diagnostics as infectious (bacterial, viral, fungal, parasitic), and non-infectious (oncological, endocrine, allergic) diseases. A significant proportion of diagnostic examinations carried out by the laboratory service relates precisely to serological tests. Serological methods remain an indispensable part of ensuring the sanitary and epidemiological well-being of any country (Cosgun et al., 2018; Di Poto et al., 2018; Riboldi et al., 2018).

It should be noted that since the expiry of the introduction of a laboratory examination of patients with a diagnostic purpose, the range of used methods and technologies has significantly expanded. Scientific and technological progress has considerably increased the possibilities of laboratory diagnosis - almost all chemical and cellular components of biological materials have become available for evaluation, and available methods, technologies and equipment have made it possible to accurately characterize the state of organs and systems of the organism with a fair degree of accuracy. A whole branch of scientific and production activity was formed, which is engaged in development and manufacture of means for clinical laboratory diagnostics. Appropriate scientific and technological developments are the subject of biotechnology. Development of serological diagnostics kits is the subject of immunobiotechnology - a section of biotechnology, which aims to create diagnostic and immune drugs for the diagnosis, treatment and 
prevention of human and animal diseases. From the biotechnological position, the starting point for any serological method is the immune response. And hence one of the most important fundamental foundations of the development of serological diagnostic kits is the understanding of the pattern of the immune response to one or another antigen. Given this circumstance, information about the antigenic structure of various proteins and substances of another chemical composition that may have a diagnostic value acquires special significance. Relevant fundamental and applied research is usually preceded by the development of serological tests. Important "tools" in the development of diagnostic products are the actual carriers of the immune response - immunoglobulins. At present, the use of polyclonal antibodies in the total volume of serological studies has significantly decreased - monoclonal antibodies have appeared on the foreground, which have undeniable advantages both from the point of view of their production technology and their biological and immunochemical properties. Hybrid technology has been one of the most used biotechnology for the fourth decade (Mao et al., 2017; Camacho et al., 2018; Cortez et al., 2018). With the advent of genetic engineering, a unique opportunity was created for the purposeful design of molecular genetic systems and the production of recombinant proteins, including diagnostic purpose. Without the use of recombinant protein antigens of various origins, it is not possible to present a modern serological diagnosis. It should be noted that biomolecules used in serological tests (antibodies, antigens, etc.) do not always "work" in their free form. Often the need arises to combine such biomolecules with one another or with substances of chemical origin. To solve such problems, a wide arsenal of methods of bioorganic chemistry is used - the conjugates of biomolecules of different qualitative and quantitative composition are obtained. The development of new and improved existing methods of conjugation of biomolecules is an urgent task of biotechnology.

The works were devoted to the development of biotechnology for hybrid (synthetic) positive control samples for ELISA test-kits. The composition of the immunoassay kits have to include control samples (negative and positive). The latter is either directly to the serum (plasma) of the blood of infected persons, or a solution of specific antibodies derived from such a serum. As already noted, in the case of producing ELISA kits intended to detect specific IgG antibodies, there is no problem in obtaining positive controls, since immunoglobulins of the IgG class are the major protective antibodies in the serum of infected individuals and convulsants in relatively high titres. At the same time, for the large-scale production of immunoassay kits designed for detection of IgA and IgM antibodies, there are limitations on the availability of large amounts of starting material - IgA and IgM positive sera (Galkin \& Gorshunov, 2014; Galkin et al., 2015). An adjuvant that solves such a disorder is the usage of hybrid positive controls, including: universal synthetic positive control for IgM capture ELISA - a conjugate of normal human IgM and McAbs to the horseradish peroxidase, as well as synthetic positive control for indirect ELISA, which is designed for detection of IgM and IgA antibodies to Ch. trachomatis - a conjugate of normal human IgM (or IgA) and McAbs to the Ch. trachomatis MOMP.

Solving the task started with characterization of McAbs to HRP. For further synthesis of hybrid positive controls for IgM-capture ELISA kits the most affinity antibodies directed both to carbohydrate (McAb 195D5) and to the polypeptide portion (McAb 196B7) of HRP were used. These studies were conducted in parallel for three different methods of obtaining antibody-antibody conjugates that are widely used in biochemistry and biotechnology: 1) NHS-ether-maleimide-mediated conjugation, using succinimidyl-4-(N-maleimidomethyl) cyclohexane-1-carboxylate (SMCC) as a cross-linking agent; 2) glutaraldehyde conjugation method; and 3) periodate conjugation method. It has been shown that the use of SMCC as a cross-linking agent provides the formation of more active conjugates that formed one peak during chromatographic purification. At the same time, the conjugate obtained by the glutaraldehyde method was inhomogeneous during chromatography, it formed three groups of molecules with differrent molecular weights. Such results correlate somehow with the data of authors (Raev et al., 2015) who studied the size distribution of carbon nanoparticles that were covalently functionalized by protein macromolecules with glutaraldehyde, as well as with recommendations (Hemanson, 2008). To obtain hybrid positive controls for the ELISA kits for detecting IgA and IgM antibodies to Ch. trachomatis needed to get McAbs to the $C h$. trachomatis MOMP and examine their immunochemical properties. To solve this problem, mice of the Balb/c lines and the immunization scheme, such as the one receiving antibody antibodies, were used. As in the case of McAbs of other specificity, the required characteristic of the panel of antibodies obtained was their epitopic specificity. At the same time, analyzing the data of various authors regarding the structure and localization of MOMP in the cytoplasmic membrane, the features of the human humoral immune response to this protein (Wang et al., 2006; Vasilevsky et al., 2016), as well as the results of their own research on the competition of some McAbs with polyclonal sera of patients with urogenital chlamydiosis, it was decided to use the method of epitope mapping based on the technology of phage display (the establishment of directly amino acid residues with which antibodies interact). This study was conducted for the most affinity antibodies that competed (McAbs 291F8 and 293F4) and did not compete (McAb 296G2) with the polyclonal antibodies of the serum at the sites of antigen binding.

Consequently, at the first stage of the work, methodological approaches to obtaining hybrid positive controls for the IgM-capture ELISA kits were theoretically substantiated. It has been established that conjugates of normal human IgM and McAbs to HRP, obtained with NHS-ether-maleimide-conjugation and periodate conjugation method, are homogeneous in molecular weight, whereas the conjugate synthesized by the glutaraldehyde method contains at least three groups of close molecular mass biopolymers. Hybrid positive controls, obtained by different methods, are characterized by a higher titre compared to high titer IgM-positive serum. However, the positive control obtained with the help of the SMCC is characterized by the best titration profile (a slower decrease in the activity of the ELISA during its dilution). The feasibility has also been proved of synthesizing positive controls on the basis of MAT, aimed at the various chemical nature of the epitopes of the hormone peroxidase molecule: carbohydrate residues and the polypeptide chain.

The resulting set of data allowed us to reasonably select McAb 296G2 for use in hybrid positive control for ELISA kits as this antibody in the positive control should not compete with polyclonal antibodies at the site of binding to the sorbed antigen. Further experiments to determine the optimal method for obtaining hybrid controls also confirmed the greater effectiveness of the NHS-ether-maleimide-mediated conjugation method.

\section{Conclusions}

The methodological approaches to obtaining synthetic positive controls for the IgM-capture immuno-enzymatic analysis are theoretically substantiated, namely: NHS ether-maleimide-mediated conjugation, using SMCC as a cross-linking agent, glutaraldehyde and periodate bioconjugation methods. It has been established that conjugates of normal human IgM and monoclonal antibodies to the horseradish peroxidase obtained with NHS ether-maleimide-mediated conjugation and periodate method are homogeneous in molecular weight, whereas the conjugate synthesized by the glutaraldehyde method contains at least three groups of close molecular biopolymers masses. Synthetic positive controls, obtained by different methods, are characterized by a higher titre compared to highlylabeled IgM-positive serum. However, the positive control obtained with the help of SMCC is characterized by the best titration profile (more slowly decreasing the activity of the ELISA during its dilution). The methodological approaches to obtaining synthetic positive controls for indirect enzyme-linked immunosorbent assays for the detection of IgM and IgA antibodies to Ch. trachomatis are substantiated, namely: NHS ether-maleimide-mediated conjugation, using SMCC as a cross-linking agent, glutaraldehyde and periodate bioconjugation methods. It was found that synthetic positive controls obtained by different methods are characterized by a higher titre compared to high-level serum containing IgM and IgA antibodies to $C h$. trachomatis. However, the positive control obtained with SMCC is characterized by the best titration profile (slower decrease in activity of ELISA during its dilution) both at the time of its receipt and after its storage at elevated temperature. The high activity of hybrid positive controls open up opportunities for increasing the efficiency of ELISA kits. 


\section{References}

Camacho, S. A., Sobral-Filho, R. G., Aoki, P. H. B., Constantino, C. J. L., \& Brolo, A. G. (2018). Zika immunoassay based on surface-enhanced raman scattering nanoprobes. ACS Sensors.

Cortez, M. M., Rojas, G. C., Parkhouse, R. M. E. (2018). The HP10 Taenia monoclonal antibody-based ELISA detects a similar protein in the vesicular fluid of Taenia hydatigena. Tropical Animal Health and Production, 50(3), 697-700.

Cosgun, Y., Guldemir, D., Coskun, A., Yolbakan, S., Kalaycioglu, A.T., Korukluoglu, G., \& Durmaz, R. (2018). The importance of serological and molecular analyses for the diagnosis of measles cases and for meeting elimination targets in Turkey from 2007 to 2015. Epidemiology and Infection. 14, 1-6.

De Carolis, S., Tabacco, S., Rizzo, F., Perrone, G., Garufi, C., Botta, A., Salvi, S., Benedetti Panici, P., \& Lanzone, A. (2017). Association between false-positive TORCH and antiphospholipid antibodies in healthy pregnant women. Lupus, 961203317741564.

Di Poto, C., He, S., Varghese, R. S., Zhao, Y., Ferrarini, A., Su, S., Karabala, A., Redi, M., Mamo, H., Rangnekar, A. S., Fishbein, T. M., Kroemer, A. H., Tadesse, M. G., Roy, R., Sherif, Z. A., Kumar, D., \& Ressom, H. W. (2018) Identification of race-associated metabolite biomarkers for hepatocellular carcinoma in patients with liver cirrhosis and hepatitis C virus infection. PLoS One, 13(3), e0192748.

Dovgan, I., Kolodych, S., Koniev, O., \& Wagner, A. (2016). 2-(Maleimidomethyl)-1,3-dioxanes (MD): A serum-stable self-hydrolysable hydrophilic alternative to classical maleimide conjugation. Scientific Reports, 6, 30835.

Galkin, O. Y., \& Gorshunov, Y. V. (2014). Otsinka metodiv biokoniuhatsii dlia otrymannia syntetychnykh pozytyvnykh kontroliv dlia imunofermentnoho analizu modyfikatsii "IgM-pastka" [Evaluation of bio-conjugation methods for obtaining of synthetic positive control for IgM-capture ELISA]. Visnyk of Dnipropetrovsk University, Biology, Medicine, 5(2), 85-89 (in Ukrainian).

Galkin, O. Y., Besarab, A. B., \& Lutsenko, T. N. (2017). Characteristics of enzymelinked immunosorbent assay for detection of IgG antibodies specific to Chlamydia trachomatis heat shock protein (HSP-60). Ukrainian Biochemical Journal, 89(1), 22-30.

Galkin, O. Y., Gorshunov, Y. V., \& Besarab, O. B. (2015). Syntetychni pozytyvni kontroli imunofermentnykh naboriv dlia vyiavlennia IgA ta IgM antytil do Chlamydia trachomatis [Synthetic positive controls for ELISA test kits for detection of IgA and IgM antibodies to Chlamydia trachomatis]. Visnyk of Dnipropetrovsk University, Biology, Medicine, 6(1), 3-8 (in Ukrainian).

Galkin, O. Y., Gorshunov, Y. V., Besarab, O. B., \& Ivanova, O. M. (2018). Development and characterization of highly informative ELISA for the detection of IgG and IgA antibodies to Chlamydia trachomatis. Ukrainian Biochemical Journal, 90(3), 49-62.

Galkin, O. Y., Savchenko, A. A., Nikitina, K. I., \& Dugan, O. M. (2013). Obtaining and study of properties of new monoclonal antibodies against human IgE. Ukrainian Biochemical Journal, 85(5), 81-87.

Hermanson, G. T. (2008). Bioconjugate techniques. Academic Press, San Diego.

Holmes, D. A., Purdy, D. E., Chao, D. Y., Noga, A. J., \& Chang, G. J. (2005) Comparative analysis of immunoglobulin M (IgM) capture enzyme-linked immunosorbent assay using virus-like particles or virus-infected mouse brain antigens to detect IgM antibody in sera from patients with evident flaviviral infections. Journal of Clinical Microbiology, 43(7), 3227-3236.

Hunsperger, E. A., Yoksan, S., Buchy, P., Nguyen, V. C., Sekaran, S. D., Enria, D. A., Pelegrino, J. L., Vázquez, S., Artsob, H., Drebot, M., Gubler, D. J., Halstead, S. B., Guzmán, M. G., Margolis, H. S., Nathanson, C. M., Rizzo,
L. N. R., Bessoff, K. E., Kliks, S., \& Peeling, R. W. (2009). Evaluation of commercially available anti-dengue virus immunoglobulin $\mathrm{M}$ tests. Emerging Infectious Diseases, 15(3), 436-440.

Kalayu Yirga, S., Ling, S., Yang, Y., Yuan, J., \& Wang, S. (2017). The preparation and identification of a monoclonal antibody against citrinin and the development of detection via indirect competitive ELISA. Toxins (Basel), 9(3), e110.

Kamel, R. M. (2013). Screening for Chlamydia trachomatis infection among infertile women in Saudi Arabia. Intemational Joumal Women's Health, 5, 277-284.

Lu, B., \& Yang, Y. (2016). Detection of TORCH pathogens in children with congenital cataracts. Experimental and Therapeutic Medicine, 12(2), 1159-1164.

Mao, L., Li, W., Zhou, T., Yang, L., Hao, F., Li, J., Zhang, W., Luo, X., \& Jiang, J. (2017). Development of a blocking ELISA for Caprine parainfluenza virus type 3. Journal of Virological Methods, 250, 59-65.

Nikolaenko, I. V., Galkin, A. J., Raevskaja, G. E., Donskaja, E. S., Kas'janenko, T. V., Tereshhenko, M. I., \& Spivak, N. J. (2005). Poluchenie monoklonalnyih antitel k Fc-fragmentu IgG cheloveka i primenenie immunofermentnyih kon'yugatov na ih osnove [Preparation of monoclonal antibodies to Fc-fragments of human IgG and usage of its conjugates in immunoassays]. Clinical Laboratory Diagnostics, 11, 8-11 (in Russian).

Nikolayenko, I. V., Galkin, O. Y., Grabchenko, N. I., \& Spivak, M. Y. (2005) Preparation of highly purified human IgG, IgM, and IgA for immunization and immunoanalysis. Ukrainica Bioorganica Acta, 2(2), 3-11.

Numan, O., Vural, F., Aka, N., Alpay, M., \& Coskun, A. D. (2015). TORCH seroprevalence among patients attending Obstetric Care Clinic of Haydarpasa Training and Research Hospital affiliated to Association of Istanbul Northern Anatolia Public Hospitals. Northern Clinics of İstanbul, 2(3), 203-209.

Raev, M. B., Khramtsov, P. V., \& Bochkova, M. S. (2015). Investigation into size distribution of carbon nanoparticles covalently functionalized with proteins. Nanotechnologies in Russia, 10, 140-148.

Reesink-Peters, N., Ossewaarde, J., Van Der Zee, A. G. J., Quint, W., Burger, M., \& Adriaanse, A. (2001). No association of anti-Chlamydia trachomatis antibodies and severity of cervical neoplasia. Sexually Transmitted Infections, 77(2), 101-102.

Riboldi, E., Carvalho, F., Romão, P. R. T., Barcellos, R. B., Bello, G. L., Ramos, R. R., de Oliveira, R. T., Júnior, J. P. A., Rossetti, M. L., \& Dallegrave, E. (2018). Molecular method confirms canine Leishmania infection detected by serological methods in non-endemic area of Brazil. Korean Journal of Parasitology, 56(1), 11-19.

Tijssen, P. (1985). Practice and theory of enzyme immunoassays. Laboratory Techniques in Biochemistry and Molecular Biology, 15, 674.

Vasilevsky, S., Stojanov, M., Greub, G., \& Baud, D. (2016). Chlamydial polymorphic membrane proteins: Regulation, function and potential vaccine candidates. Virulence, 7(1), 11-22.

Vazquez, S., Hafner, G., Ruiz, D., Calzada, N., \& Guzman, M. G. (2007). Evaluation of immunoglobulin $\mathrm{M}$ and $\mathrm{G}$ capture enzyme-linked immunosorbent assay Panbio kits for diagnostic dengue infections. Journal of Clinical Virology, 39(3), 194-198.

Wang, Y., Berg, E. A., Feng, X., Shen, L., Smith, T., Costello, C. E., \& Zhang, Y. X (2006). Identification of surface-exposed components of MOMP of Chlamydia trachomatis serovar F. Protein Science, 15(1), 122-134.

Yang, H., Dai, R., Zhang, H., Li, C., Zhang, X., Shen, J., Wen, K., \& Wang, Z. (2016). Production of monoclonal antibodies with broad specificity and development of an immunoassay for microcystins and nodularin in water. Analytical and Bioanalytical Chemistry, 408(22), 6037-6044. 